\title{
Clinical Reasoning: West syndrome, pontocerebellar hypoplasia, and hypomyelination in a 6-month-old boy
} Parayil Sankaran Bindu, DM, Madhu Nagappa, DM, Shwetha Chiplunkar, MBBS, Periyasamy Govindaraj, PhD,
Pavagada S. Mathuranath, DM, Sanjib Sinha, DM, and Arun B. Taly, DM

Neurology ${ }^{\circledR}$ 2018;91:e1652-e1656. doi:10.1212/WNL.0000000000006381

\section{Section 1}

A 6-month-old boy born to nonconsanguineous parents presented with intractable seizures from the fourth month of age. Oligohydramnios was detected in the last trimester of pregnancy. He was born at term by normal delivery (birthweight $2.9 \mathrm{~kg}$ ). At birth he had weak cry, microcephaly (head circumference $31 \mathrm{~cm}$, <third centile), micrognathia, prominent nasal bridge, and radial deviation of both hands. Cranial and abdominal ultrasonogram and echocardiogram were normal.

The patient developed infantile spasms at 4 months of age recurring every hour in clusters of 3-5 spasms, each lasting 1-2 minutes. Developmental milestones were limited to partial head control at 5 months. At 6 months, he had head circumference of $37 \mathrm{~cm}$ (<third centile), metopic ridging, hypertelorism, puffy cheeks, high-arched palate, micrognathia, short stubby digits, basal syndactyly of second and third toes, bilateral ankle contracture, and a small café-aulait spot on his left leg anteriorly. He had pendular nystagmus, poor visual tracking, normal fundi, generalized spasticity, bilateral ankle clonus, and extensor plantar response.

\section{Questions for consideration:}

1. What are the possible etiologies you will consider in this child?

2. What are the investigations that help to narrow down the differential diagnoses?
Correspondence

Dr. Bindu

drpsbindu@yahoo.co.in

GO TO SECTION 2

From the Department of Neurology (P.S.B., M.N., P.G., P.S.M., S.S., A.B.T.) and Neuromuscular Lab-Neurobiology Research Center (P.S.B., M.N., S.C., P.G., A.B.T.), National Institute of Mental Health and Neurosciences, Bangalore, India.

Go to Neurology.org/N for full disclosures. Funding information and disclosures deemed relevant by the authors, if any, are provided at the end of the article. 


\section{Section 2}

The clinical features in this child are consistent with epileptic encephalopathy (EE). ${ }^{1}$ The etiologies are heterogeneous and include birth insults, structural brain malformations, and inborn errors of metabolism in the majority. ${ }^{2}$ When these most common etiologies are addressed, a genetic cause should be investigated. ${ }^{1}$

EEG or video EEG helps to delineate the epilepsy syndrome. Brain MRI is useful in detecting congenital malformations, tuberous sclerosis, and perinatal hypoxic or hypoglycemic injury. Magnetic resonance spectroscopy can identify specific metabolic defects. ${ }^{2}$ A tiered approach is useful for investigation of metabolic etiologies. ${ }^{3}$

When MRI and metabolic testing do not point to a definite etiology, other genetic EEs should be considered. The investigations include testing for copy number variations by high density single nucleotide polymorphism array, comparative genomic hybridization array, and exome sequencing. The selection of the testing depends on the clinical characteristics, seizure phenotypes, and syndromic diagnosis.
MRI in this child demonstrated hypomyelination, and hypoplasia of brainstem and cerebellum (figure, A-C). EEG showed hypsarrhythmia with episodes of attenuation (figure, D). Metabolic testing including serum ammonia, lactate, biotinidase, homocysteine, uric acid, amino acids, and acyl carnitine profile, and urine organic acids were negative. Karyotyping and fluorescence in situ hybridization analysis of chromosome 22 was negative. Chromosomal microarray was not carried out. The patient was diagnosed with West syndrome with pontocerebellar hypoplasia (PCH) and hypomyelination.

The patient was treated with optimal dosages of levetiracetam, sodium valproate, and clonazepam along with pyridoxine (120 $\mathrm{mg}$ ), without substantial benefit. Administration of intramuscular ACTH for 6 weeks led to partial seizure control. No specific antispasticity medications were given. At 1 year of age, he had profound psychomotor retardation, uncontrolled generalized, myoclonic, and tonic seizures, and persistent hypsarrhythmia.

\section{Questions for consideration:}

1. Based on these findings, what are the differential diagnoses?

2. What testing could clarify the diagnosis? 

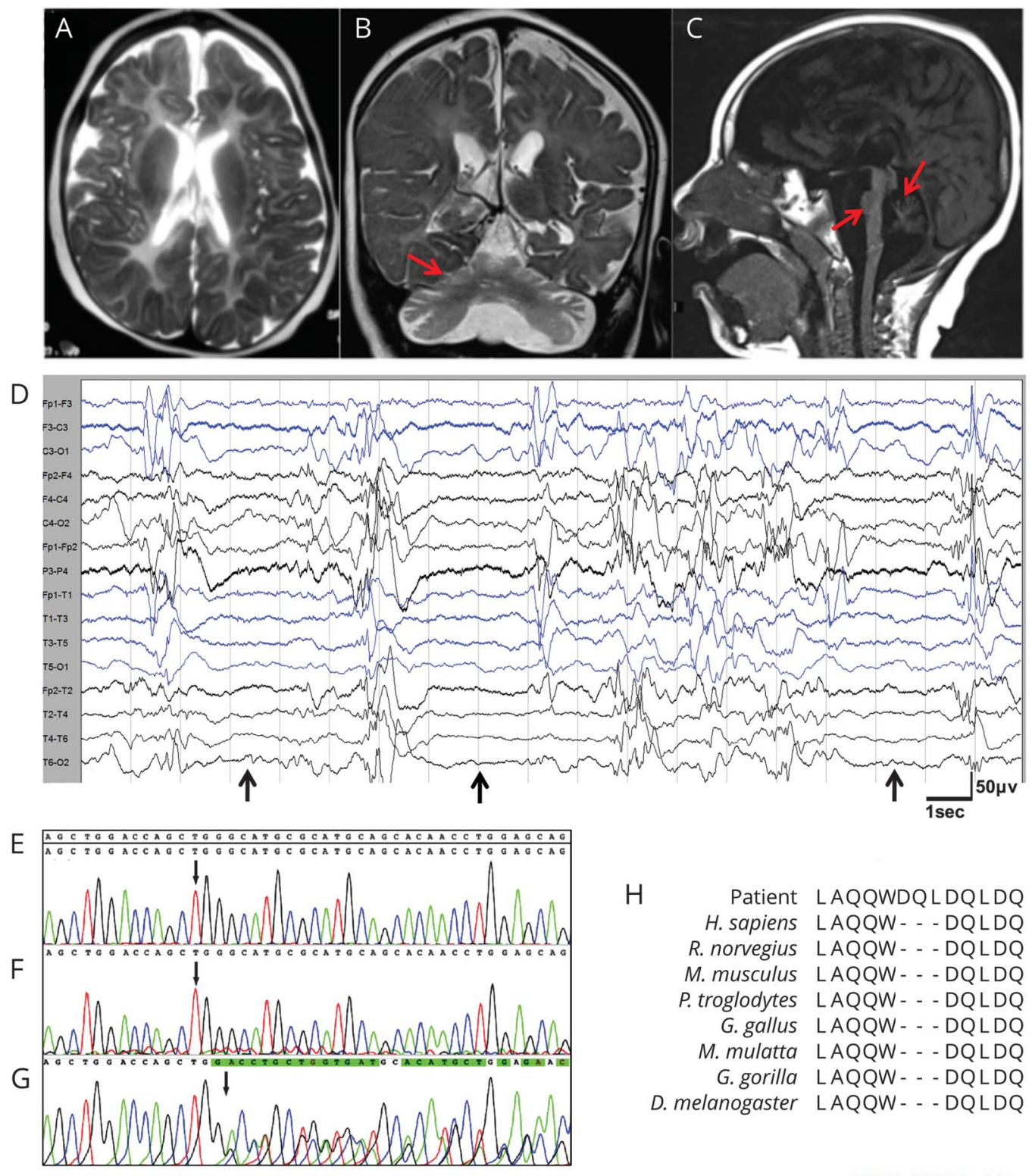

H Patient LAQQWDQLDQLDQ

H. sapiens LAQQW - - DQLDQ

R. norvegius LAQQW - - DQLDQ

M. musculus LAQQW - - - DQLDQ

P. troglodytes LAQQW - - - DQLDQ

G. gallus LAQQW - - - DQLDQ

M. mulatta LAQQW - - DQLDQ

G. gorilla LAQQW - - DQLDQ

D. melanogaster LAQQW - - - DQLDQ

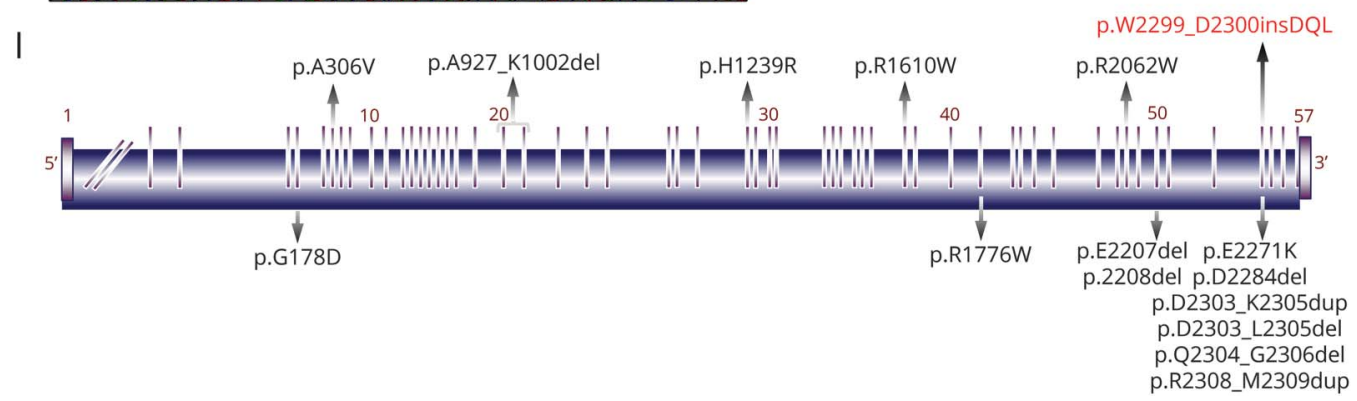

(A-C) MRI at 6 months of age (A) and 1 year (B, C). (A) T2-weighted axial view shows diffuse hypomyelination. (B) T2-weighted coronal image demonstrates cerebellar hypoplasia (arrows). (C) T1-weighted sagittal image shows pontine and cerebellar hypoplasia (arrows). (D) EEG at 6 months of age shows hypsarrhythmia with episodes of attenuation (arrows). (E-G) Sequence chromatogram and alignment to the reference variation in parents (E, F) and the index patient (G) show 9bp insertion only in the patient. (H) Conservation of the region across species. (I) Variations reported in SPTAN1. Adapted from Sybre et al. ${ }^{9}$ Mutation described in the present report is shown in red. 


\section{Section 3}

To further narrow down the differential diagnoses in this child, the specific MRI findings- $\mathrm{PCH}$ and hypomyelination-are helpful.

What are the differential diagnoses of $\mathrm{PCH}$ on MRI?

Genetic etiologies of PCH can be divided into 2 groups ${ }^{4}$ :

1. Cerebellar hypoplasia and variable cortical atrophy: $\mathrm{PCH}$ types 1-10, phosphoserine aminotransferase deficiency, progressive encephalopathy with edema, hypsarrhythmia, and optic atrophy (PEHO) syndrome, SPTAN1 encephalopathy, and congenital disorders of glycosylation IA and ID.

2. Cerebellar hypoplasia plus neocortical dysplasia: dystroglycanopathies, CASK-related disorders, and tubulinopathies.

The clinical features of the main $\mathrm{PCH}$ syndromes include the following: $\mathrm{PCH} 1-$ severe hypotonia, bulbar dysfunction, respiratory insufficiency, congenital contractures with anterior horn cell involvement; $\mathrm{PCH} 2$-dystonia and extrapyramidal disorder and seizures; $\mathrm{PCH} 3$-progressive microcephaly, optic atrophy, seizures, and hypotonia; $\mathrm{PCH} 4$ - severe perinatal symptoms, congenital contractures, primary hypoventilation, and early postnatal death; $\mathrm{PCH} 5$ - intrauterine seizure-like activity and a predominantly affected vermis; PCH6 - EE, hypotonia, and elevated lactate levels. Of all the PCH types, the presence of EE in this child favors a diagnosis of PCH6.

Phosphoserine aminotransferase deficiency is a rare inborn error of serine synthesis. ${ }^{5}$ Typical presentation is that of an infantile encephalopathy with refractory seizures, progressive microcephaly, and MRI demonstrating $\mathrm{PCH}$ and poor white matter development. A normal plasma amino acid profile along with CSF serine levels would help to exclude this.

PEHO syndrome is another condition with $\mathrm{PCH}$ where an association with RARS2 and SPTAN1 gene variations has been suggested. ${ }^{4}$ Congenital disorders of glycosylation rarely cause EE and MRI shows cerebellar hypoplasia along with a bright cerebellum.

While the second group of disorders is unlikely in view of the absence of cortical malformations, CASK-related disorder is still a possibility. A severe phenotype with intellectual disability, microcephaly and $\mathrm{PCH}(\mathrm{MCPCH})$, and early infantile EE (EIEE) has been described in boys. ${ }^{6}$

The next step will be to consider the second MRI feature in this child; namely, hypomyelination.

What are the differential diagnoses for hypomyelination?
Hypomyelinating disorders are divided into the following:

1. Primary hypomyelinating disorders: Pelizaeus-Merzbacher disease, Pol III-related leukodystrophy, hypomyelination with congenital cataract, 18q-syndrome, fucosidosis. Even though isolated seizures occur in some of these disorders, $\mathrm{EE}$ as a dominant clinical manifestation is generally not a feature of these disorders.

2. Neuronal disorders with secondary hypomyelination ${ }^{7}$ : neuronal ceroid lipofuscinosis, EIEE 39 caused by SLC25A12, AIMPI-related disorder, GM1 and GM2 gangliosidosis, SPTAN1 encephalopathy, and $\mathrm{PCH}$ subtypes.

Among the above disorders with variable combination of EE, $\mathrm{PCH}$, and hypomyelination, $\mathrm{PCH}$ subtypes, especially type 6, and SPTAN1- and CASK-related disorders might be considered high in the differentials, given the predominant clinical manifestation of EE in this child. Based on these broad differential diagnoses, a clinical exome-sequencing panel that covers the $\mathrm{EE}, \mathrm{PCH}$, and other metabolic disorders not covered in the metabolic screening was requested.

Exome sequencing revealed a heterozygous 9 base pair insertion in exon 53 of the SPTAN1 gene (c.6896 6897insGGACCAGCT) that resulted in insertion of 3 amino acids between codon 2,299 and 2,300 (p.Trp2299 Asp2300insAspGlnLeu) that was validated by Sanger sequencing. This is situated in the functionally important heterodimer domain of the SPTAN1. This variation was not present in the 1,000 genomes, gnomad, or ExAC database. It was not detected in the parents, suggesting a de novo occurrence (figure, E-G). The variation was predicted to be damaging by Mutation Taster 2. The region is conserved across the species (figure, $\mathrm{H}$ ).

\section{Discussion}

Mutations in SPTAN1, implicated in etiology of EIEE-5 (OMIM \#613477), were first described in $20100^{8}$ Since then, 34 patients with SPTAN1 mutations with mild and severe phenotypes have been reported. ${ }^{9}$ EIEE represents the severe form. The main seizure type is infantile spasms with a median age at onset of 4 months. Patients have seizures refractory to various modes of treatment, leading to developmental arrest. EEG shows hypsarrhythmia, which may persist up to 2-3 years or may evolve into multifocal epileptiform abnormalities. Premature and sudden unexpected death has been reported. Patients with mild phenotypes have childhoodonset myoclonic or focal seizures and less severe intellectual disability. Systemic features include edematous extremities simulating PEHO syndrome, coloboma of optic discs, atrial septal defects, and myocarditis. ${ }^{8-10}$

MRI demonstrates a variable combination of cerebral, brainstem, and cerebellar atrophy, hypomyelination, and thin 
corpus callosum. Patients with EIEE often exhibit progressive atrophy and hypomyelination, while patients with milder phenotype may have normal MRI or mild atrophy. ${ }^{9}$

The mutational spectrum of SPTAN1 includes missense, inframe deletions/duplications (figure). ${ }^{10}$ All patients with EIEE have amino acid changes and in-frame deletions/ duplications located in $\alpha$-II spectrin repeats a 16-20, as exemplified in this patient. They demonstrate severe progressive brainstem and cerebellar atrophy with hypomyelination. Mutations have also been described outside the heterodimer domain and these patients have less severe phenotype and MRI abnormalities. ${ }^{9}$

SPTAN1 (spectrin $\alpha$, nonerythrocytic 1) codes for $\alpha$-II spectrin, which is a major component of the membrane cytoskeleton. It has an important role in stabilizing nascent sodium channel clusters and assembling the mature node of Ranvier. ${ }^{10}$ Mutant $\alpha$-II spectrins cause aggregation and failure of heterodimerization of $\alpha$ and $\beta$ spectrins, leading to severe functional disruption in neurons resulting in the neurologic manifestations. $^{8} \alpha$-II spectrin mutants also show impaired myelination in motor nerves and dorsal spinal cord, suggesting their role in myelination. Pathobiology in patients with milder phenotypes has not been elucidated so far.

SPTANI encephalopathy comprises a broad spectrum of developmental disorders with epilepsy. Familiarity with its phenotypes and MRI may facilitate early recognition, genetic counseling, and prognostication.

\section{Author contributions}

P.S. Bindu: study concept and design, data analysis and interpretation, wrote the manuscript, critical revision of the manuscript for important intellectual content, approved final draft. M. Nagappa: data analysis and interpretation, critical revision of the manuscript, approved final draft. S. Chiplunkar: data collection and interpretation, approved final draft. P. Govindaraj: data analysis, interpretation, approved final draft. S. Sinha: data analysis, revision of the manuscript, approved final draft. P.S. Mathuranath: data analysis and interpretation, critical revision of the manuscript. A.B. Taly: study supervision, critical revision of the manuscript for important intellectual content, approved final draft.

\section{Study funding}

No targeted funding reported.

\section{Disclosure}

The authors report no disclosures relevant to the manuscript. Go to Neurology.org/N for full disclosures.

\section{References}

1. McTague A, Howell KB, Cross JH, Kurian MA, Scheffer IE. The genetic landscape of the epileptic encephalopathies of infancy and childhood. Lancet Neurol 2016;15: 304-316.

2. Sharma S, Prasad AN. Genetic testing of epileptic encephalopathies of infancy: an approach. Can J Neurol Sci 2013;40:10-16.

3. Sharma S, Prasad AN. Inborn errors of metabolism and epilepsy: current understanding, diagnosis, and treatment approaches. Int J Mol Sci 2017:18.

4. Namavar Y, Barth PG, Poll-The BT, Baas F. Classification, diagnosis and potential mechanisms in pontocerebellar hypoplasia. Orphanet J Rare Dis 2011;6:50.

5. Hart CE, Race V, Achouri Y, et al. Phosphoserine aminotransferase deficiency: a novel disorder of the serine biosynthesis pathway. Am J Hum Genet 2007;80:931-937.

6. Saitsu H, Kato M, Osaka H, et al. CASK aberrations in male patients with Ohtahara syndrome and cerebellar hypoplasia. Epilepsia 2012;53:1441-1449.

7. Pouwels PJ, Vanderver A, Bernard G, et al. Hypomyelinating leukodystrophies: translational research progress and prospects. Ann Neurol 2014;76:5-19.

8. Saitsu H, Tohyama J, Kumada T, et al. Dominant-negative mutations in alpha-II spectrin cause West syndrome with severe cerebral hypomyelination, spastic quadriplegia, and developmental delay. Am J Hum Genet 2010;86:881-891.

9. Syrbe S, Harms FL, Parrini E, et al. Delineating SPTAN1 associated phenotypes: from isolated epilepsy to encephalopathy with progressive brain atrophy. Brain 2017;140: 2322-2336.

10. Tohyama J, Nakashima M, Nabatame S, et al. SPTAN1 encephalopathy: distinct phenotypes and genotypes. J Hum Genet 2015;60:167-173. 


\section{Neurology}

\section{Clinical Reasoning: West syndrome, pontocerebellar hypoplasia, and hypomyelination in a 6-month-old boy \\ Parayil Sankaran Bindu, Madhu Nagappa, Shwetha Chiplunkar, et al. \\ Neurology 2018;91;e1652-e1656 \\ DOI 10.1212/WNL.0000000000006381}

This information is current as of October 22, 2018

\section{Updated Information \& Services}

References

Subspecialty Collections

Permissions \& Licensing

Reprints including high resolution figures, can be found at: http://n.neurology.org/content/91/17/e1652.full

This article cites 9 articles, 0 of which you can access for free at: http://n.neurology.org/content/91/17/e1652.full\#ref-list-1

This article, along with others on similar topics, appears in the following collection(s):

All Epilepsy/Seizures

http://n.neurology.org/cgi/collection/all_epilepsy_seizures

All Genetics

http://n.neurology.org/cgi/collection/all_genetics

All Pediatric

http://n.neurology.org/cgi/collection/all_pediatric

Developmental disorders

http://n.neurology.org/cgi/collection/developmental_disorders

MRI

http://n.neurology.org/cgi/collection/mri

Information about reproducing this article in parts (figures,tables) or in its entirety can be found online at:

http://www.neurology.org/about/about_the_journal\#permissions

Information about ordering reprints can be found online:

http://n.neurology.org/subscribers/advertise

Neurology ${ }^{\circledR}$ is the official journal of the American Academy of Neurology. Published continuously since 1951, it is now a weekly with 48 issues per year. Copyright (O) 2018 American Academy of Neurology. All rights reserved. Print ISSN: 0028-3878. Online ISSN: 1526-632X.

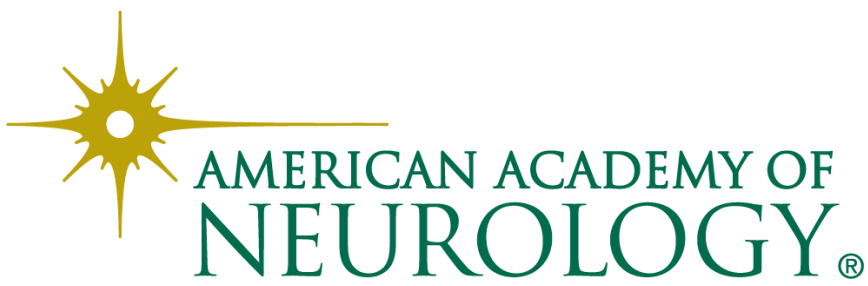

